\title{
An Assessment of Post-Legislative Scrutiny Recommendations in the UK Parliament
}

Post-legislative scrutiny allows Parliament to revisit legislation after it has been enacted to ensure that it is operating as intended. As most literature on the UK legislative process suggests that is not optimal, this is an important task that committees can undertake to ensure that any problems can be located and rectified. This paper reports the findings of a systematic study of the outcomes of post-legislative scrutiny in terms of the types of recommendations being made, whether they are being accepted by the government, and what factors impact upon the acceptance of those recommendations. It concludes that there is a bias in the legislation being selected to receive post-legislative scrutiny and that committees on the whole are producing weaker recommendations which are more likely to be accepted. Additionally it concludes that the stronger the action that a recommendation calls for, the more likely it is to be rejected.

Key Words: Post-legislative scrutiny, legislation, committees, review, accountability, recommendations

\section{Introduction}

One of the main roles of legislatures around the world is to create laws, however it is also a legislature's role to evaluate whether the laws that they pass are meeting the objectives set at the time of passage through the legislative process (De Vrieze \& Hasson, 2017). Postlegislative scrutiny is defined by the Law Commission of England and Wales as;

A broad form of review, the purpose of which is to address the effects of legislation in terms of whether intended policy objectives have been met by the legislation and, if so, how effectively. However this does not preclude 
consideration of narrow questions of a purely legal or technical nature. (Law Commission, 2006)

Post-legislative scrutiny as such is one of the core tasks of departmental select committees (House of Commons Liaison Committee, 2012). In the last decade a more systematic approach has been taken by both government and parliament. With regards to the House of Commons, since 2008 government departments have been required to prepare and publish memoranda, assessing whether an Act of Parliament has met its key objectives, within three to five years of the Act entering the statute books (Cabinet Office, 2012; Kelly, 2014; Kelly \& Everett, 2013). These memoranda are then presented to departmental select committees for additional scrutiny. With regards to the House of Lords, in 2012 the Liaison Committee promised to appoint at least one ad hoc committee per session to undertake post-legislative scrutiny on a subject chosen by it (House of Lords Liaison Committee, 2012).

Currently, due to a lack of systematic scrutiny we do not know what types of recommendations committees are making or whether they are being accepted. This research will address the following research questions: which Acts have been selected for post-legislative scrutiny; what recommendations have arisen from post-legislative scrutiny; how frequently have these recommendations been accepted by the government; and what factors impact upon the acceptance of these recommendations?

This article aims to address this gap in knowledge by assessing the recommendations from all 20 full post-legislative scrutiny inquiries between 2005 and 2017 in terms of their type and the strength of actions called for, as well as using an ordinal logistic regression to determine what factors are significant in the acceptance of recommendations. So far only government introduced legislation has been reviewed through post-legislative scrutiny, as such the inquiries 
in this research all relate to government legislation. This research shouldn't just be of interest to those who study legislatures and committee systems but also to those who study the policy process and the evaluation of public policy.

This research makes several contributions. It contributes to our understanding of postlegislative scrutiny as a task of parliamentary committees, this is an important contribution as currently there is limited academic literature on post-legislative scrutiny. Indeed to my knowledge, this is the first systematic study of post-legislative scrutiny. However it also has a practical contribution to make on the basis that post-legislative scrutiny is in the process of becoming more formalised in other legislatures, as such this research is important in providing an assessment of the system that the UK Parliament has decided to introduce and could have a major impact upon decisions in other legislatures around the world about whether the UK's system is worth modelling. It also contributes more broadly to the existing literature on the impact of oversight committees (Benton \& Russell, 2013; MacMahon, 1943; Rockman, 1984). It also extends the work of Benton and Russell (2013) by assessing the impact oversight committees have with regards to post-legislative scrutiny in particular and additionally addresses the operation of parliamentary committees in the UK Parliament as a whole, as this study includes committees in both the Commons and the Lords.

\section{Existing studies}

To date the academic study of post-legislative scrutiny, both in the UK and internationally, has been limited. However while there is a lack of literature on post-legislative scrutiny there is a wider literature on the broader impact of parliamentary oversight committees. Such 
parliamentary committees are the main vehicle through which post-legislative scrutiny in the UK Parliament is undertaken.

Academics have taken various approaches when studying and assessing the impact of scrutiny in the UK (White, 2015b). They have measured the impact of committees using indicators such as; whether committee recommendations are being accepted; whether references to committee work are being made during parliamentary proceedings; whether amendments to bills stem from committee recommendations; as well as citations of committee work in judicial decisions and whether the media has mentioned the work of committees (White, 2015b).

Tolley's (2009) study into the work of the Joint Committee on Human Rights (JCHR) assessed the extent to which the JCHR contributes to more informed debate and prevents governments from passing the legislation it wants without agreeing to any changes the JCHR recommends. Tolley did so by measuring how many references there were to the Joint Committee during floor debates in both Houses of Parliament and also the extent to which the Joint Committee's recommendations went on to influence legislative and judicial outcomes (Tolley, 2009). Tolley (2009) found that in most instances the Government did not consider the views of the Committee during the drafting stages of legislation and that there was an inability of the Committee to be able to prevent the Government from passing bills (Tolley, 2009; White, 2015b).

Hawes' (1993) study on the influence of committees on environmental policies used case studies and the analysis of interviews, on top of government responses to committee reports. The study found that 60 per cent of recommendations went on to be accepted by the government although he also concluded that select committee influence is not always direct or visible and can also take place over a long period of time. However a number of researchers and authors have noted the problem of using a simple assessment of the acceptance of recommendations as an indicator of impact (Baines, 1985; Drewry, 1985; Giddings, 1985). Such problems include: 
weak recommendations skewing the results as they are more likely to be accepted (Aldons, 2000); the government agreeing to accept but then not implement; and finally the government initially rejecting recommendations only to go on an implement them anyway (Hawes, 1992). That being said while the assessment of recommendations does not tell the whole picture, it does still show how the government is responding to them and if there is a pattern in the way it responds.

There have however been attempts to deal with this problem. Hindmoor, Larkin, \& Kennon (2009) when assessing how influential the House of Commons Education Committee assessed the initial government response and whether the recommendation was implemented in legislation (but didn't measure non-legislative measures). They also identified a number of measures to assess the impact and influence of the Committee on four sets of actors; government, parliament, the media and political parties (Hindmoor et al., 2009). They put these findings into context by interviewing both politicians and civil servants. They concluded that while there were examples of the Committee having an impact on, and influencing policy, a pattern of influence was harder to pinpoint (Hindmoor et al., 2009; White, 2015b).

Benton \& Russell (2013) undertook a comprehensive study of the policy impact of select committees in the House of Commons. They utilised a mixed methods approach which included the coding of media coverage of select committees and the coding of recommendations, and the acceptance and implementation of recommendations from the reports of seven select committees between 1997 and 2010 (Benton \& Russell, 2013; Russell \& Benton, 2011). Benton \& Russell (2013) also undertook 56 semi-structured interviews with committee chairs and members as well as committee staff and civil servants in order to explore less quantifiable parts of select committee influence (Russell \& Benton, 2011). The study found that of the recommendations which were clearly aimed at central government, 40 per cent of them were formally accepted, they also found that around 44 per cent of measurable 
recommendations went on to be implemented. It is this study which forms the methodological foundation for this research.

\section{Hypotheses}

These hypotheses are based upon the findings of the previous studies listed above which addressed the impact of parliamentary committees.

1. The stronger action that a recommendation calls for, the more likely it is to be rejected by the government.

Here 'stronger action' refers to the scale of action that the committee requests from the government in its recommendation (e.g. calls for more information to be released versus calls for amendments to primary legislation). This is intuitive to some degree but it is also a measure that Benton \& Russell (2013) addressed in their study which showed just that. Benton \& Russell (2013) noted in their research that committees may deploy a strategy of producing weaker recommendations that the government is more likely to accept and as a result make committees appear more influential. This is also a strategy that is acknowledged by Aldons (2000). Therefore such a finding might provide some evidence that would explain the behaviour of committees.

2. Recommendations calling for disclosure and guidance will be more likely to be accepted by the government. 
Again Benton \& Russell (2013) used such measures and found that disclosure and guidance were statistically significant and were more likely to be accepted. It is also expected on the basis that disclosing information is part of the main relationship between government departments and committees and should therefore be seen as a routine request. Additionally, it might be expected that recommendations calling for disclosure and guidance would be ranked as weaker recommendations and, as a result of hypothesis one, be more likely to be accepted because they are weaker and as such are more palatable to the government.

3. Recommendations calling for action relating to legislation will be more likely to be rejected by the government.

Due to the nature of post-legislative scrutiny and the focus on legislation, it is also expected that calls for action relating to legislation will be more likely to be rejected on the basis of the time and political capital investment that such changes would require. Action relating to legislation refers to recommendations that explicitly call for legislative action, including the amendment or repeal of existing legislation, putting things on a 'statutory footing', and changes to secondary legislation. This is again linked to the strength of recommendation categories that recommendations calling for action relating to legislation are likely to fall under. Benton \& Russell (2013) also used this variable although it was not found to be statistically significant, however with post-legislative scrutiny focusing on legislation, it is expected that legislative style recommendations might be more prevalent leading to a more significant relationship.

4. If a bill is contentious it will be more likely to have recommendations rejected by the government. 
It is expected that bills considered to be contentious will be more likely to see their recommendations rejected on the basis that they are likely to be stronger. It is probable that the government will not want to reopen issues that it considered closed following the completion of the formal legislative process.

\section{Data and methods}

Post-legislative scrutiny inquiries were located on House of Commons and House of Lords committee websites for all sessions between the 2005/2006 and 2016/2017 sessions. Following the location of these inquiries a content analysis of reports was undertaken in order to code committee recommendations and the government's response to those reports. This involved the coding of 20 reports and 20 government responses.

The recommendations were selected from those appearing in the recommendation/conclusion section at the end of a committee's report. Recommendations were coded in terms of which organisations they were directed at, with the focus upon those directed at central government. Following this set of coding it was determined that some recommendations called for more than one action. In order to ensure that government responses could be matched correctly with recommendations, they were broken down into their various calls for action. Following this there were 504 recommendations in total. Once formal recommendations directed at central government had been identified each recommendation was coded on the type of recommendation made, using a coding scheme deployed by Russell and Benton (2011). Additionally the strength of change that the recommendation calls for was also coded. This employed a modified version of Russell and Benton's (2011) coding scheme (no/small, medium and large change), with the scale increased to five on the basis of the types of changes that post-legislative scrutiny calls for. The medium action category was expanded into three 
separate categories (medium a, b and c) to account for the differences in action classified under the medium category (e.g. calls for more resources1 versus calls for the amendment of primary legislation), as defined by Russell and Benton (2011). Additionally the no/small category has been separated into no action and small action, to account for the difference between no change and small change. The categories used to measure strength of recommendation for this study are; (0) no action, (1) small action, (2) medium a action, (3) medium b action, (4) medium c action and (5) large action (see appendices for a full breakdown of coding descriptors). All reports were double coded and a sample of committee reports were coded outside of the research team to ensure coder reliability.

To code the government responses, each response was matched with the corresponding recommendation. As with the codes for type of recommendation and strength of recommendation, the codes for government acceptance (the dependent variable) were based upon those utilised by Russell \& Benton (2011). Here the code descriptions have been altered slightly to ensure relevance for post-legislative scrutiny but the scale has not been increased as with strength of recommendation. The categories used to measure government acceptance are; (1) rejected outright, (2) rejected in part, (3) neither accepted nor rejected, (4) accepted in part and (5) accepted outright.

The independent variables2 utilised in the regression analysis are split into three categories, the committee level and recommendation level, and the legislative level. At the committee level, variables included; opposition chairman; Joint Committee; Justice Committee, Public

\footnotetext{
${ }^{1}$ In this study, recommendations were classified as resource related if they explicitly called for (additional) funding or savings, including the continuation of funding for existing programmes or reallocation of funding. 2 The following independent variables were not included due to problems with multicollinearity (as measured by the VIF diagnostics in SPSS): party of Government (which introduced the legislation); departmental select committees (as a combined category, although individual committees were included); ad hoc committees; Culture, Media and Sport Committee; length of Act (in words); time difference between Royal Assent and post-legislative scrutiny and time spent in the House of Commons.
} 
Administration and Constitutional Affairs Committee; Home Affairs Committee; government majority on the committee. These variables were selected on the basis that they were included in the research of Russell and Benton (2011), however the types of committee selected here are based upon those committees that had undertaken post-legislative scrutiny. The types of committee were included to assess whether any specific committees were significant in the acceptance (or indeed rejection) of recommendations. Finally whether committees had an opposition chairman, and whether they had a government majority were included to explore the impact that they might have on the acceptance of recommendations.

At the legislative level variables included: number of sittings in committee stage (in the House of Commons)3; number of government defeats in the House of Lords4 and contentiousness. These variables were included on the basis that what happened to those Acts as they passed through the legislative process might have an impact upon the recommendations committees make and the government's acceptance of them. The number of sittings in committee offers an insight into the depth of scrutiny an Act received as it passed through the House of Commons and the number of defeats in the House of Lords could give an indication of the level of changes the Lords were willing to push for against the government's wishes in order to improve the Act. Finally the contentiousness of the legislation during the legislative process was included to determine the impact of this variable on the likely acceptance of recommendations. Finally, at the recommendation level, variables included the strength of recommendations and the different types of recommendations which include; action related to legislation; guidance; policy/procedural change; research; disclosure and resources. These variables were used by

\footnotetext{
3 For this particular variable, the post-legislative scrutiny inquiry into adoption legislation reviewed two pieces of legislation. To deal with this an average was taken of the number of sittings in committee. It was determined to be the best way to move forward without excluding or skewing the data.

4 Note the footnote above, this time in relation to the number of government defeats in the House of Lords.
} 
Benton and Russell (2011) and were included to explore the significance of the different types of recommendations upon their likely acceptance.

The recommendation level variables are dummy variables based upon the data on types of recommendations that committees called for. The committee level variables were collated from the membership sections of post-legislative scrutiny committee reports and through totalling the number of committees that had undertaken post-legislative scrutiny. The data for the legislative level variables came from Sessional Returns (House of Commons) and Public Bill Statistics (House of Lords). The data for the contentious variable came from Hansard and is based upon whether a division was called at either second and/or third reading in the House of Commons and also whether there has been a rebellion of more than five per cent of MPs from the major parties in those divisions. The five per cent threshold was selected to discount the times when only a couple of MPs (e.g. out of over 100) would vote against their party. A rebellion of five per cent or more would signify that there was a problem within that party's parliamentary group and was not just the 'usual suspects'. Second and third readings were chosen as they are the opportunities MPs have to vote on Acts as a whole package.

Additionally, this quantitative data is supplemented with qualitative semi-structured interviews with five Clerks from both the House of Commons and House of Lords. These Clerks were selected on the basis that their committees had undertaken a full post-legislative scrutiny inquiry during the 2010 or 2015 Parliaments to ensure reliable recall.

\section{Analysis}

17 out of the 20 Acts which have been subject to post-legislative scrutiny were introduced under the 1997-2010 Labour Governments, with only two pieces of legislation being introduced by the 2010-2015 Coalition Government. To some extent this is not surprising as 
the 2008 system, as noted in the introduction, required the production of a memorandum by the relevant government department within three to five years of an Act entering the statute books. As such during the first half of the 2010 Parliament, it would have been Labour Government legislation that was receiving departmental post-legislative review. However we are now well beyond the first half of the 2010 Parliament and the legislation of the 2010-2015 Coalition Government should now be receiving departmental post-legislative review. It should also be noted that not all post-legislative scrutiny is driven by memoranda published by government departments under the systematic process as committees can and do select legislation to receive post-legislative scrutiny without receiving a post-legislative memorandum first. So there is no procedural obstacle that could stop committees addressing the legislation of the 2010-2015 Coalition Government.

This suggests that there might be some bias in the selection of legislation that receives postlegislative scrutiny on the basis that some of the legislation of 2010-2015 Coalition Government now falls into the three-five year timeframe for post-legislative review by a government department. However the subsequent memoranda from these reviews do not appear to be getting picked up by committees. This raises the question of whether this is a result of the party in government at the time. From sessional returns seventy Acts of Parliament from both the 2010-2012 and 2012-2013 sessions should now have received post-legislative review by the relevant government department (House of Commons, 2012;2013) as it has been over five years since those Acts received Royal Assent. However, only two of those Acts have received post-legislative scrutiny (three per cent) so far. Additional research is required here to determine whether the issue is that post-legislative review memoranda are not being published in a timely manner by government departments. However, as noted previously, committees are not required to wait until they receive a post-legislative review memoranda from a government department before undertaking post-legislative scrutiny. 
The Government's response to the Law Commission's 2006 report on post-legislative scrutiny noted the need for more systematic post-legislative scrutiny (Office of the Leader of the House of Commons, 2008) however it does not appear to have been fully achieved. While more postlegislative scrutiny inquiries are taking place, a rolling programme of post-legislative scrutiny does not appear to be occurring.

\section{[Table one near here]}

It might be expected that post-legislative scrutiny would lead to a greater number of recommendations calling for action in relation to legislation, whether that is implementing an unimplemented part of an act, or amending or repealing part of an Act. However only 79 recommendations out of 504 called for action related to the legislation (16 per cent) but legislative change is arguably the most costly for governments. That being said, one reason given in interviews for why so few recommendations call for legislative change, was that so far 'the vast majority of post-legislative scrutiny inquires have concluded that the primary and secondary legislation under scrutiny is operating as intended' (Interview with a Clerk of a House of Lords ad hoc committee; Interview with the Clerk of the House of Lords Liaison Committee). The problems identified in the post-legislative scrutiny inquiries 'appear to have come from poor implementation' (Interview with a Clerk of a House of Lords ad hoc committee). However this does raise other questions around whether the most suitable legislation (the legislation in greatest need of review) is being selected for post-legislative scrutiny, not just in terms of there being a party bias, but because the general academic and practitioner view is that legislative scrutiny in the UK is not optimal (Brazier, Kalitowski, \& Rosenblatt, 2007; Fox \& Korris, 2010; Rippon, 1993; Slapper \& Kelly, 2015). This raises the question of whether the literature is over exaggerating the problem and failing to acknowledge other areas of influence (Russell et al., 2015 and Thompson, 2015). 


\section{[Table 2 near here]}

In fact the most frequent type of recommendation called for is a change in policy or practice, with 39 per cent of recommendations calling for such action. This is less surprising since departmental select committees focus upon government policy and getting a government to change legislation is a costly way to spend political capital. As such committees focus on what they are more likely to achieve. It also suggests that that committees are calling for recommendations which are more likely to be accepted and this leads them to make a greater policy difference. There is also an acknowledged difficulty in getting whole committees to 'agree to stronger action' (Interview with a Clerk of a House of Commons Committee 1). The second most frequent type of recommendation which committees called for was for research to be conducted or for a more extensive review to be undertaken. Again it was noted in research interviews that it is not unusual for a committee to make such recommendations, especially if they feel 'they do not have sufficient evidence to make a direct call for action' (Interview with a Clerk of a House of Commons Committee 1; Interview with a Clerk of a House of Commons Committee 2).

\section{[Table 3 near here]}

In terms of the strength of recommendations table three shows that 41 per cent of recommendations stemming from post-legislative scrutiny inquiries called for little or no action on behalf of the government and there were only seven recommendations out of 504 that were classified as calling for a large action. Committees will also be aware that they do not have the power to force the government to accept and implement their recommendations. All they have is the power to persuade. Further research is necessary to determine how far the persuasive powers of committees stretch. This suggests that committees are hedging their bets and 
recommending small and medium actions which are more likely to be accepted and implemented and thus have more of an impact. This is acknowledged by both Aldons (2000) and Benton \& Russell (2013) and may also explain the lack of legislative style recommendations in table one, as well. However Clerks suggest that the reason for these findings is that the Acts reviewed between 2010 and 2016 have been given a clean bill of health. Indeed the interviews suggest that problems with the Acts were a result of "poor implementation rather than problem with the underlying legislative framework' (Interview with a Clerk of a House of Lords ad hoc committee; Interview with the Clerk of the House of Lords Liaison Committee). As noted above this does raise concerns about whether the legislation which has been selected for post-legislative scrutiny so far has been the most in need of review, especially considering the criticisms there are of the quality of legislation that Parliament produces (Brazier, Kalitowski, \& Rosenblatt, 2007; Fox \& Korris, 2010; Rippon, 1993; Slapper \& Kelly, 2015).

\section{[Table 4 near here]}

In total 39 per cent of recommendations were accepted (either in full or in part). This is perhaps not surprising as the majority of recommendations called for small or medium action. 36 per cent of recommendations were rejected at least in part, if not outright. Additionally 10 per cent of recommendations did not receive a response at all. This is a substantial proportion of recommendations which have not received a response from the government and presents an opportunity for the government to skirt around issues which it does not want to tackle head on and wishes to kick into the long grass. However the government should ensure that it directly responds to each recommendation and state clearly what it intends to do. This would help with accountability when a committee follows up on recommendations. However committees also need to ensure that the recommendations they produce call for clear action, so the government can respond effectively. 
Unsurprisingly table five shows that recommendations are more likely to be accepted if they are coded small or medium action, with those calling for greater action more likely to be rejected. When it comes to recommendations calling for no and small action 64 per cent and 53 per cent of them are either accepted in part or in full. For recommendations which are classified under medium (a) 44 per cent of them being accepted in part or in full and 35 per cent of them being rejected in part or in full.

\section{[Table 5 near here]}

Additionally when focusing on the recommendations which call for stronger action there is a greater percentage of them rejected either in part or in full. For medium action (b) 43 per cent of them are rejected, as opposed to 27 per cent which are accepted. Medium (b) also sees the largest number of recommendations which are neither accepted nor rejected. This is unsurprising, as at this level of strength the government may wish to kick the issue into the long grass so they can study it in more detail before accepting or rejecting, or do nothing and hope that the committee forgets. When it comes to recommendations classified under medium (c) (calling for higher medium action), 77 per cent were rejected in part or in full in comparison to 17 per cent of which that were accepted in part or in full. Finally on recommendations calling for large action, 85 per cent were rejected in part or in full and none were accepted either in part or in full.

An ordinal logistic regression was utilised as it was appropriate for the dependant variable. The analysis shows that four variables are statistically significant, one at the $\mathrm{P}<0.001$ level and one at the $\mathrm{P}<0.05$ level with an additional two variables at the $\mathrm{P}<0.1$ level (this was included due to the small $\mathrm{n}$ ). The categories used to measure government acceptance are; (1) rejected outright, (2) rejected in part, (3) neither accepted nor rejected, (4) accepted in part and (5) 
accepted outright. The coding scheme for this dependent variable (and other recommendation related schemes) can be found in the appendices.

Strength of recommendation was statistically significant at the $\mathrm{P}<0.001$ level in this model. The directionality of this variable is negative meaning that stronger recommendations are more likely to be rejected than accepted. This is in line with hypothesis one. These findings are in line with the findings of Benton \& Russell (2013) in their study on the impact of parliamentary oversight committees. This finding also suggests that if committees do deploy a strategy as suggested by Aldons (2000) and Benton \& Russell (2013), then they are not completely wrong to do so. The time committees, especially departmental select committees, have to undertake their variety of functions is limited and if they were producing recommendations calling for stronger action which were subsequently being rejected, then it would raise the question of what is the point in doing such scrutiny if the main recommendations are just going to be rejected anyway.

\section{[Table 6 near here]}

However, rather than a deliberate strategy at play regarding the of couching recommendations in terms that the government can more readily accept, interviews suggested that committees are producing weaker recommendations due to internal political compromise on the committee, as a unanimous report is more influential (all of the reports in this study were agreed unanimously). It is not possible with the data and documents currently available to measure the extent to which committees are compromising. This is an area which requires further in-depth research. White (2015a) notes that committees are at their most effective when they present a cross-party consensus. That sometimes means that they prefer a weaker recommendation on which they can all agree, rather than a stronger one which would cause a division. Additionally the desire to seeking compromise with the Government will have an impact here too, as 
committees recognise that they won't get everything they want and judge that it would be better to get something than nothing. Finally a lack of evidence on which to develop a recommendation would also lead to a committee producing weaker recommendations (Interview with a Clerk of a House of Commons Committee 1).

When asking committee staff how much attention they pay to the government's likely response to a recommendation before making it, they noted 'that at times they do pay some attention to this factor', but it does vary from issue to issue and from committee to committee (Interview with a Clerk of a House of Commons Committee 2; Interview with a Clerk of a House of Commons Committee 3). Additionally, the idea of seeking compromise with the government to an extent is being strategic and they are as a result altering their behaviour based upon what they believe the government will likely accept. That being said, Clerks also noted that if a committee views a recommendation as important, they will go on and make it anyway, regardless of the government's likely response to it.

Committee chairman was statistically significant at the $\mathrm{P}<0.05$ level and the directionality was negative meaning committee chairs who were opposition MPs at the time of the inquiry were more likely to see their recommendations rejected than accepted. This might be due to the nature of post-legislative scrutiny in reviewing legislation as the legislative process is partisan and that partisanship on the part of the government may filter into this particular task.

The regression analysis also showed that joint committees were significant at the $\mathrm{P}<0.1$ level. The directionality of the variable is negative, suggesting that recommendations coming from joint committees are being rejected by the government. This correlation can be explained by the nature of the inquiry undertaken by the committee in question. The inquiry was on terror legislation and as a result of it being a sensitive area, the government will, as a result, be more likely to reject changes to the Act and its operation. 
Finally, sittings in committee was significant at the $\mathrm{P}<0.1$ level and its directionality was positive suggesting that the more sittings in committee there were the more likely it is for its recommendations to be accepted. This could be down to the additional scrutiny that the Act received during its time in the House of Commons, it might make the government more likely to accept recommendations.

\section{Conclusion}

This research has found that there is bias in the selection of legislation that receives postlegislative scrutiny, this has important implications on the ability of the UK Parliament to refer to its post-legislative scrutiny as systematic as there is currently a gap in coverage. This is on the basis that some of the legislation of 2010-2015 Coalition Government would now fall into the three-five year timeframe for post-legislative review by a government department. However only two inquiries between 2005 and 2017 have reviewed this government's legislation. This raises the question of whether legislation is being selected is most suitable (i.e. there is clearly something wrong with the operation of the Act) on the basis of the general academic literature on the UK legislative process suggesting it produces deficient legislation. Additionally, this research found that only 79 recommendations out of 504 called for action related to the legislation and its implementation (14 per cent). This is surprising considering the criticisms made of the legislative process and the quality of the legislation that it produces. This also raises questions about the selection of such legislation, considering the literature on the UK legislative process.

The research also considered the strength of action that recommendations call for and found that committees tend to focus their recommendations on calling for small and medium action. This suggests that committees are hedging their bets and recommending small and medium 
actions which are more likely to be accepted and implemented and thus have an impact. This is a strategy acknowledged by both Aldons (2000) and Benton \& Russell (2013), it is also a strategy that appears to be supported somewhat by other findings from the research. This contributes to our understanding of committee behaviour. This paper also found that 39 per cent of recommendations were accepted (either in full or in part), this is not surprising as the majority of recommendations called for small or medium action. This figure was in line with what Benton \& Russell (2013) found in their study. This suggests that there is some limited impact here, however as noted earlier, this is a crude way to measure committee impact.

In terms of the regression analysis for government acceptance, the analysis suggested that there is a very strong relationship between the strength of recommendations and their acceptance. The directionality of this variable is negative meaning that stronger recommendations are more likely to be rejected than accepted. This is in line with what is hypothesised and this finding was also in line with the findings of Benton \& Russell (2013) in their study on the impact of parliamentary oversight committees. This finding could also suggest that if committees do deploy a strategy as suggested by Aldons (2000) and Benton \& Russell (2013), then from their perspective they are not completely wrong to do so the basis that the analysis shows that stronger recommendations are more likely to be rejected. While interviews did provide some reasons for why the data might be showing what it does, such as committees seeking a compromise with the government on the basis that it's better to get something than nothing, this would also suggest that committees were altering their behaviour in response to the government's anticipated actions. Again this contributes to our understanding of committee behaviour as well as the impact of parliamentary committees. Ultimately these findings also have implications for the replication of such post-legislative scrutiny mechanisms in other legislatures. While there is room for impact, as Benton \& Russell's (2013) research shows, there is a problem with the selection of Acts to receive post-legislative scrutiny. As a result of 
this and the fact that the current process in the House of Commons is ten years old this year, the UK Parliament should review the legislation it selects for post-legislative scrutiny with the aim of addressing this gap in coverage.

Further research is also necessary in terms of determining the overall influence of postlegislative scrutiny, through assessing the implementation of post-legislative recommendations. More in depth research is also necessary in terms of the potential biases around the selection of legislation and more broadly on the strategic choices that committees are or are not making.

\section{References}

Aldons, M. (2000). 'Rating the Effectiveness of Parliamentary Committee Reports'. Legislative Studies. 15: 22-32.

Baines, P. (1985). 'History and Rationale of the 1979 Reforms'. In G. Drewry (ed.). The New Select Committees: A Study of the 1979 Reforms. Oxford: Clarendon Press.

Benton, M., \& Russell, M. (2013). 'Assessing the Impact of Parliamentary Oversight Committees: The Select Committees in the British House of Commons'. Parliamentary Affairs. 66 (4): 772-797.

Brazier, A., Kalitowski, S., \& Rosenblatt, G. (2007). Law in the Making: A discussion paper. London: Hansard Society. 
Cabinet Office. (2012). Guide to Making Legislation. July 2012. Available at: https://www.gov.uk/government/uploads/system/uploads/attachment_data/file/210917/Guide to_Making_Legislation_July_2013.pdf. (Accessed on: 8th February 2014).

De Vrieze, F \& Hasson, V. (2017). Post-legislative scrutiny: Comparative study of practices of Post-Legislative Scrutiny in selected parliaments and the rationale for its place in democracy assistance. London: Westminster Foundation for Democracy.

Drewry, G. (1985). 'Introduction’. In G. Drewry (ed.). The New Select Committees: A Study of the 1979 Reforms. Oxford: Clarendon Press.

Fox, R \& Korris, M. (2010). Marking Better Law: Reform of the legislative process from policy to Act. London: Hansard Society.

Giddings, P. (1994). 'Select Committees and Parliamentary Scrutiny: Plus Ça Change'. Parliamentary Affairs. 47 (4): 669-686.

Hawes, D. (1992). 'Parliamentary Select Committees: Some Case Studies in Contingent Influence'. Policy and Politics. 20: 227-236.

Hawes, D. (1993). Power on the Back Benches? The Growth of Select Committee Influence. Bristol: SAUS.

Hindmoor, A., Larkin, P., \& Kennon, A. (2009). 'Assessing the Influence of Select Committees in the UK: The Education and Skills Committee 1997-2005'. Journal of Legislative Studies. 15 (1): 71-89.

House of Commons. (2012). Sessional Returns: Session 2010-2012. 14th September 2012. HC 1 . 
House of Commons. (2013). Sessional Returns: Session 2012-2013. 13th September 2013. HC 1.

House of Commons Liaison Committee. (2012). Select committee effectiveness, resources and powers. 8th November 2012. HC 697. 2010-2012.

House of Lords Liaison Committee. (2012). Review of select committee activity and proposals for new committee activity. $21_{\mathrm{st}}$ March 2012. HL 279. 2010-12.

Kelly, R. (2014). Modernisation: Select Committees - pay for chairs. House of Commons Library Standard Note. SN/PC/02725. 19th February 2014.

Kelly, R., \& Everett, M. (2013). Post-Legislative Scrutiny. House of Commons Library Standard Note. SN/PC/05232. 23rd May 2013.

Law Commission. (2006). Post-legislative scrutiny. October 2006. Cm 6945.

MacMahon, A. W. (1943). 'Congressional Oversight of Administration: The Power of the Purse'. Political Science Quarterly. 58 (2): 161-190.

Office of the Leader of the House of Commons. (2008). Post-Legislative Scrutiny - The Government's Approach. March 2008. Cm 7320.

Rippon, G. (1993). Making the Law: The Report of the Hansard Society Commission on the Legislative Process. London: Hansard Society.

Rockman, B. A. (1984). 'Legislative-Executive relations and Legislative Oversight'. Legislature Studies Quarterly. 9 (4): 387-440.

Russell, M., \& Benton, M. (2011). Selective Influence: The Policy Impact of House of Commons Select Committees. London: Constitution Unit. 
Russell, M., Gover, D., \& Wollter, K. (2015). 'Does the Executive Dominate the Westminster Legislative Process?: Six Reasons for Doubt'. Parliamentary Affairs. 69 (2): 286-308

Slapper, G., \& Kelly, D. (2015). The English Legal System (15th ed.). Abingdon: Routledge.

Thompson, L. (2015). Making British Law: Committees in Action. Basingstoke: Palgrave MacMillan.

Tolley, M. (2009). 'Parliamentary Scrutiny of Rights in the United Kingdom: Assessing the Work of the Joint Committee on Human Rights'. Australian Journal of Political Science. 44 (1): 41-55.

White, H. (2015b). Parliamentary Scrutiny of Government. London: Institute for Government.

\section{Appendices}

\section{Coding Schemes}

Detailed below are some of the important codes that have been referred to in the main body of the article. The coding schemes were tested and trailed and each recommendation was double coded to ensure validity.

Strength of action called for

Captures the strength of the action which the recommendations called for, this took place on a six point scale. 
0) No Action - for recommendations which support or endorse existing policy and/or legislation.

1) Small Action - for recommendations which call for information to be released, for guidance to be issued/amended and for reviews, assessments and further consideration to be taken.

2) Medium (a) - for recommendations which call for a pause in a policy, for a pilot/trail run to be undertaken, for a change in practice, for additional resources or training to be made available, for the implementation of parts of an Act and for existing legislation to be utilised.

3) Medium (b) - for recommendations which call for policy changes, new regulations or for regulations to be amended and for minor amendments to be made to an Act (e.g. for drafting purposes).

4) Medium (c) - for recommendations which call for substantial amendments (relating to powers) or for the repeal of specific clauses of an Act, additionally for recommendations which call on the Government to legislate but do not specifically call for primary legislation.

5) Large - for recommendations that call for the repeal of all or part of an Act or for new legislation to be introduced. 
Captures the extent to which the recommendations produced by committees were accepted by the government, this took place on a six point scale.

(0) No response - for recommendations that did not receive a direct written response within the Government's response, or for recommendations which are not acknowledged explicitly or implicitly in the government's response.

(1) Rejected outright - for recommendations where the government states that it rejects or disagrees or through its response signals outright rejection.

(2) Partially rejected - for recommendations that were part rejected and part ignored, or where the government dodged the point the recommendation made, including suggestions that the recommendation was not necessary. Additionally for recommendations where the government rejects but acknowledges frustration or where the government states that it has a policy/initiative (which is different to what the recommendation calls for) already in place to deal with the issue raised by the recommendation.

(3) Neither accepted nor rejected - for recommendations which were accepted in part and rejected in part. Also for recommendations which received lukewarm support (e.g. saying the recommendation required further consideration) or where it is not clear whether the recommendation is accepted or rejected. 
(4) Partially accepted - for recommendations where there was agreement with the general thrust (in principle) but not the finer detail which the committee called for. Also for recommendations which were accepted in part and ignored in part. Finally for recommendations where the government accepts the objective or principle of a recommendation but proposes an alternative policy or initiative to that recommended by the report.

(5) Fully accepted - for recommendations where the government states that it accepts or agrees, or through its response signals full acceptance or for recommendations where the government claimed the committee's demands were already in progress. 